Article

\title{
The Changing Selenium Nutritional Status of Chinese Residents
}

\author{
Sumei $\mathrm{Li}^{1}$, Gary S. Bañuelos ${ }^{2}$, Longhua $\mathrm{Wu}^{1}$ and Weiming Shi ${ }^{1, *}$
}

1 State Key Laboratory of Soil and Sustainable Agriculture, Institute of Soil Science,

Chinese Academy of Sciences, Nanjing 210008, China; E-Mails: smli@issas.ac.cn (S.L.); lhwu@issas.ac.cn (L.W.)

2 USDA, Agricultural Research Service, San Joaquin Valley Agricultural Sciences Center, Parlier, CA 93648, USA; E-Mail: Gary.Banuelos@ARS.USDA.GOV

* Author to whom correspondence should be addressed; E-Mail: wmshi@issas.ac.cn; Tel.: +86-25-8688-1566; Fax: +86-25-8688-1000.

Received: 16 December 2013; in revised form: 20 February 2014 / Accepted: 3 March 2014 / Published: 14 March 2014

\begin{abstract}
The selenium (Se) content in human hair is useful as an indicator of human $\mathrm{Se}$ intake and status. In this regard, when measuring the hair Se concentrations in Chinese inhabitants across northeast to southeast China, the results indicated that generally $84 \%$ of all residents have normal hair Se content. Between the sexes, the average hair Se content of males was higher than that of females, irrespective of districts. When comparing geographical regions, the average hair Se content of southern residents was greater than that of northern residents, regardless of gender. Historically, the overall hair Se content of today's inhabitants decreased between $24 \%$ and $46 \%$ when compared with the inhabitants living in the same geographic region 20 years ago. The decrease of hair Se content may be related to the overall decrease of grain consumption and the lower Se content in the staple food rice.
\end{abstract}

Keywords: hair Se content; historical Se data; grain consumption

\section{Introduction}

Selenium is an essential trace element in human nutrition [1]. China, for example, is one of the 40 countries designated as low Se or Se deficient according to World Health Organization (WHO) [2]. The Se deficient areas account for 72\% of the country's total area, its deficiency affects over 70 million people who face the potential adverse health impacts due to Se deficiency [3]. Overt Se 
deficiency has caused serious health consequences in low Se areas of China, such as endemic Keshan disease (endemic cardiomyopathy) and Kaschin-Beck disease (endemic osteoarthropathy) [4]. Meanwhile, there is mounting evidence that suggests the importance of Se in the functioning of the immune system, counteracting the development of virulence, inhabiting HIV progression to AIDS, protecting against cardiovascular disease [1], mitigating and preventing the teratogenic effects exerted by such metals as $\mathrm{Cd}, \mathrm{Hg}, \mathrm{Pb}$, and $\mathrm{As}$ [5], and even preventing the development of tumors and reducing the risk of some types of cancer [6].

Selenium enters the food chain through plants and the amount of Se in foods is directly affected by Se levels in the soil in which they are grown [5]. Intake of Se varies considerably between countries and regions of countries largely due to the variability of the Se content of plant foods from one part of the world to another. Grain, as staple food, plays a crucial role in the food supply in China, and it is also an efficient way to provide Se to consumers, i.e., Korea [7], Japan [8]. In the last century, 70\% of the Se intake of rural Chinese residents came from their staple diet [9]; after 2000, cereals were still major Se source food in the daily diet with the development of the economy, such as $23 \%$ in the Suzhou area [3], a developed area in China.

The concentration of Se in hair is a commonly-used index to evaluate body Se load, as it reflects the long-term Se level of the human body [10]. Hair Se had highly significant correlations with the Se concentration in muscle $(R=0.89, n=15)$, whole blood $(R=0.90)$, red blood cells $(R=0.91)$, blood plasma $(R=0.87)$ and toenails $(R=0.85)[3,11]$. Hair Se can also be used as an important indicator on endemic diseases and may play a critical role in the etiologic research on the Keshan disease, Kashin-Beck disease, and on local selenosis in China [12]. Furthermore, hair Se content was found to regularly increase from the Keshan disease zone $(<0.20 \mu \mathrm{g} / \mathrm{g})$ to the transition zone $(0.20-0.25 \mu \mathrm{g} / \mathrm{g})$ and to the non-disease zone $(>0.25 \mu \mathrm{g} / \mathrm{g})$ [13]. These values reflect the close relationship between the geographical distribution of hair Se and Keshan disease.

The present study aims: (1) to evaluate the Se nutritional status of Chinese residents by conducting a systematic survey on hair Se concentrations of residents crossing 10 provinces from northeast to southeast China; (2) to compare the Se nutrition of current residents with data reported in the past, and to analyze if the changes in hair Se content is due to reduced Se intake via rice as a staple food over time.

\section{Materials and Methods}

\subsection{Sample Collection and Preparation}

Hair and food samples were collected from the local residents in suburbs or cities. According to Se content in soil [4] we selected 10 provinces and municipalities extending from northeast to southeast China (Figure 1), including Se deficiency areas (Harbin in Heilongjiang province; Fuxin in Niaoling province; Tangshan in Hebei province; Zhengzhou in Henan province; Xian in Shaanxi province), and moderate Se areas (Shanghai municipality; Wuhan in Hubei province; Chengdu in Sichuan province; Fuzhou in Fujian province; and Nanning in Guangxi province). The selected areas are densely populated and have strong agriculture-driven economies. In every province, we selected three different residential locations to sample from urban and suburban populations, respectively, because it was impossible to practically sample on a large scale. In sampling, we balanced the sex ratio as best as 
possible, as well as age ratio: children:adults:seniors $=1: 8: 1$. To avoid obvious bias, the detailed information was collected and taken into consideration for all residents before their ethics approval for sampling (i.e., age, health, income, dwelling time). The study has been reviewed by the institutional review board of the Institute of Soil Science, Chinese Academy of Sciences and approved to proceed. Food samples were purchased from local supermarkets, including: rice, major types of vegetables, meats, and fishes. A total of 408 hair samples were collected from local healthy people of both genders ranging from 4 to 76 years old across the 10 provinces - there were 46 children (4-18 years old), 319 adults (19-60 years old) and 43 seniors (61-76 years old). Approximately $2.0 \mathrm{~g}$ of hair samples were cut between 1 and $3 \mathrm{~cm}$ from the nape of the neck. Hair samples were washed with acetone and distilled water three times, respectively, air-dried, stored, and cut into small pieces with stainless-steel scissors before digestion.

Figure 1. Distribution of $\mathrm{KSD}, \mathrm{KBD}$ (by disease-affected countries) [4] in China, including the study areas within our survey (designated with red stars).

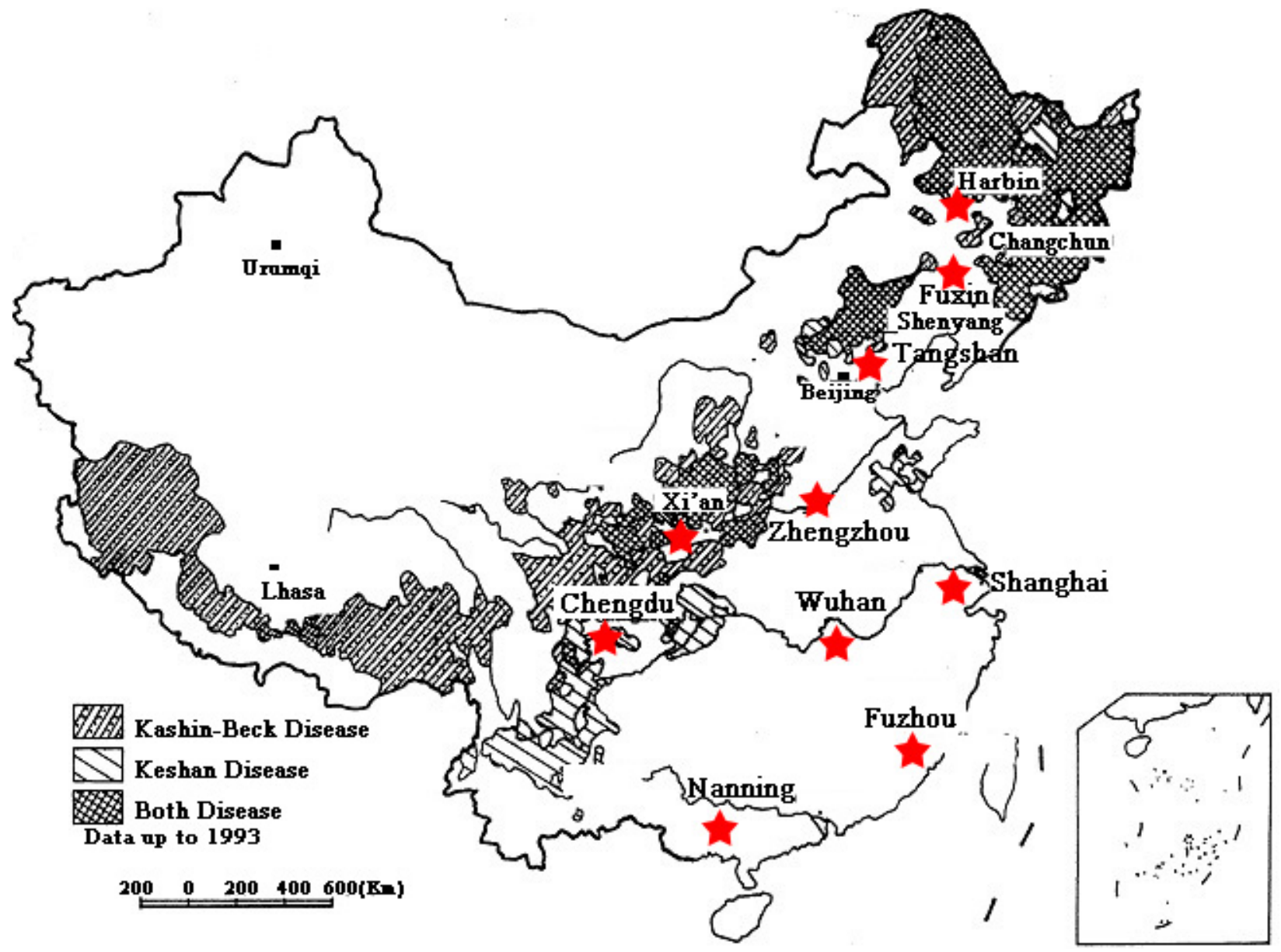

\subsection{Sample Digestion}

Samples of $0.5 \mathrm{~g}$ were weighed and placed into $50 \mathrm{~mL}$ PTFE digestion containers. Two $\mathrm{mL}$ of $\mathrm{H}_{2} \mathrm{O}_{2}$ were added and the sample container was shaken a few times to disaggregate the sample. Then, $6 \mathrm{~mL}$ of $\mathrm{HNO}_{3}$ were added and the PTFE container was shaken a few times again and mixed thoroughly. After sealing, the closed PTFE containers were left in the digestion vessel and placed at $160{ }^{\circ} \mathrm{C}$ for $8 \mathrm{~h}$. 
The sample solution was then evaporated at $130{ }^{\circ} \mathrm{C}$ until a white fume formed, and the volume of the solution was reduced to $2 \mathrm{~mL}$ on the electric evaporation block. Acid fumes were removed by a water vacuum pump and adsorbed in a strong alkaline solution. After the solution was cooled to room temperature, $5 \mathrm{~mL}$ of $50 \% \mathrm{HCl}$ were added to reduce selenate to selenite at $110{ }^{\circ} \mathrm{C}$ in the evaporation block for approximately two hours. As the solution became clear, it was transferred into a clean $15 \mathrm{~mL}$ polycarbonate tube, and filled to final volume with ultra-pure water. All hair samples were digested at least in duplicate. Two procedural (reagent) blanks were prepared with every sample digestion run. In addition, to minimize any possible contamination during sample digestion and AFS analysis, PTFE digestion vessels were washed with laboratory detergent, rinsed and soaked in $20 \% \mathrm{v} / \mathrm{v} \mathrm{HCl} \mathrm{overnight,}$ followed with a rinsing with ultra-pure water prior to sample digestion. Plastic containers, pipette tips, and test tubes used in the experimental work were soaked in $20 \% \mathrm{v} / \mathrm{v} \mathrm{HCl}$ overnight, and lastly rinsed with ultra-pure water before use.

Ultra pure water ( $\geq 18.2 \mathrm{M} \Omega$ ) from a Millipore Milli-Q system (Milford, MA, USA) was used for the preparation of all solutions. External calibration standards were prepared by gravimetric serial dilution from $1000 \mathrm{mg} / \mathrm{L}$ Se stock standard solution in $10 \% \mathrm{HCl}\left(\mathrm{NCS}^{\circledR}\right.$ analytical instruments, Beijing, China). The standard solutions were prepared at the beginning of each run with ultra-pure water and $\mathrm{HCl}$ $(50 \% \mathrm{v} / \mathrm{v})$ to a final $10 \%$ acid concentration. $2 \%(\mathrm{w} / \mathrm{v}) \mathrm{KBH}_{4}$ was prepared using $0.5 \%(\mathrm{w} / \mathrm{v}) \mathrm{NaOH}$ solution, and used as a reducing agent. All the chemical reagents used were super pure guarantee grade.

\subsection{Determination of Selenium Concentration by $H G-A F S$}

The Se concentration in each sample was determined by Hydride Generation Atomic Fluorescence Spectrometry (HG-AFS) 610D2 (Beijing Rayleigh Analytical Instrument Co., Ltd., Beijing, China). Instrumental conditions were as follows: lamp current $75 \mathrm{~mA}$, photomultiple tube negative high voltage $300 \mathrm{v}$, atomizer height $87 \mathrm{~mm}$, carrier gas flow rate $500 \mathrm{~mL} / \mathrm{min}$, and a shielding gas flow rate $100 \mathrm{~mL} / \mathrm{min}$. Procedural blanks were analyzed every two hours to monitor for variations in blank levels, and were measured after rinse solutions to minimize any memory effects.

The recovery and accuracy of the Se measurements were determinate with standard reference Se materials of rice (GBW10045), meat (GBW08552), cabbage (GBW10014) and human hair (GBW07601 GSH-1) prepared by the National Research Center for Standards in China, which contained $0.053 \pm 0.014 \mathrm{mg} \mathrm{Se} / \mathrm{kg}, 0.49 \pm 0.05 \mathrm{mg} \mathrm{Se} / \mathrm{kg}, 0.2 \pm 0.03 \mathrm{mg} \mathrm{Se} / \mathrm{kg}$ and $0.60 \pm 0.04 \mathrm{mg} \mathrm{Se} / \mathrm{kg}$, respectively. The Se recovery was between $95 \%$ and $103 \%$.

\subsection{Statistical Analysis}

Data were subjected to analysis of variance (ANOVA), and post hoc comparisons were performed with Duncan's multiple range test at $p<0.05$. The statistical software program used was SPSS version 13.0 (IBM, Armonk, NY, USA). 


\section{Results and Discussion}

\subsection{Hair Se Level of the Current Survey}

The hair Se concentrations of 408 residents across 10 provinces and cities were analyzed statistically and they formed a normal distribution (Figure 2), in which most hair Se content ranged from 0.30 to $0.45 \mathrm{mg} / \mathrm{kg}$, with a median value of $0.37 \mathrm{mg} / \mathrm{kg}$. This concentration fell between normal hair Se values $(0.36-0.74 \mathrm{mg} / \mathrm{kg})$ as reported by Schroeder [14]. Moreover, the hair Se content of residents in this study was similar to results presented in recent reports of the same region in China, i.e., $0.29 \pm 0.08$ in Heilongjiang $\mathrm{mg} / \mathrm{kg}$ (Table 1) and $0.26 \pm 0.08 \mathrm{mg} / \mathrm{kg}$ reported in 2011 [15], as well as $0.38 \pm 0.16 \mathrm{mg} / \mathrm{kg}$ in Henan (Table 1) and $0.39 \pm 0.10 \mathrm{mg} / \mathrm{kg}$ reported in 2008 for the Huaibei region [16] (one of the cities in the Anhui province adjacent to Henan). However, there was large individual variability in hair Se content of Chinese residents with a maximum value of $2.65 \mathrm{mg} / \mathrm{kg}$ and a minimum value of $0.06 \mathrm{mg} / \mathrm{kg}$; a 46 times difference between maximum and minimum. There also existed a regional difference in the hair Se content among residents (Table 1); Shaanxi had the lowest median of $0.28 \mathrm{mg} / \mathrm{kg}$, whereas Hubei had the greatest median of $0.44 \mathrm{mg} / \mathrm{kg}$. In general, hair Se content of the northern residents was lower than that of the southern residents. The hair Se content in the northern areas (Heilongjiang, Liaoning, Hebei, Henan, and Shaanxi) was 0.29, 0.36, 0.38, 0.38, and $0.29 \mathrm{mg} / \mathrm{kg}$, respectively, whereas hair Se content in the southern areas (Shanghai, Hubei, Sichuan, Fujian, and Guangxi) was $0.42,0.44,0.43,0.40$, and $0.39 \mathrm{mg} / \mathrm{kg}$, respectively (Table 1).

Figure 2. The statistical distribution of all residents' hair Se concentrations in this survey.

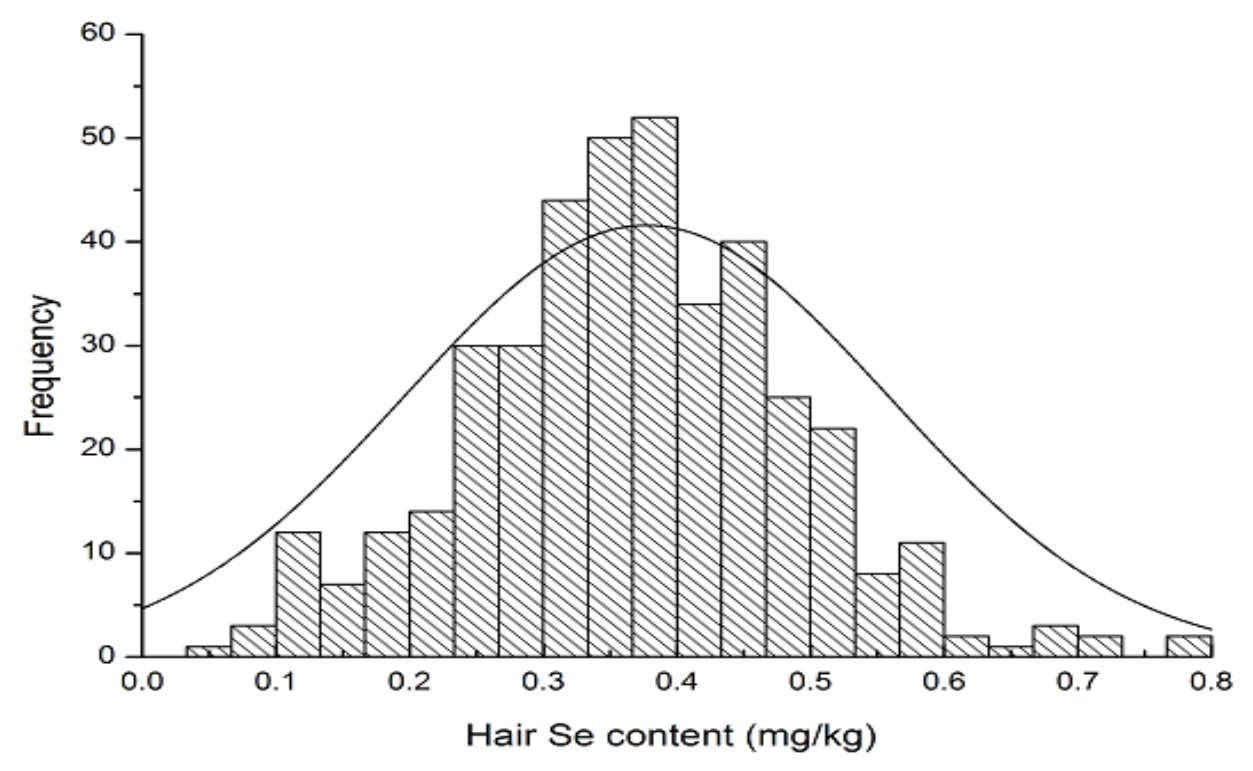

Among the 408 survey participants, generally 342 (84\%) residents had normal hair Se content according to hair Se ecological landscape value designated by past research efforts related to Se-endemic diseases in China [13]. The hair Se content of 35 residents (9\%) was lower than $0.20 \mathrm{mg} / \mathrm{kg}$, which was deemed to be in the Se deficiency status. The hair Se content of 31 residents (7\%) ranged from 0.20 to $0.25 \mathrm{mg} / \mathrm{kg}$ and was considered to be on the edge of Se deficiency (Table 2). Two residents had hair Se content greater than $1.00 \mathrm{mg} / \mathrm{kg}$, which was still below the value used to designate Se excess $(3.00 \mathrm{mg} / \mathrm{kg})$. 
Table 1. Hair Se content of residents in different Chinese districts (mg/kg).

\begin{tabular}{|c|c|c|c|c|c|c|c|c|c|c|c|c|}
\hline \multirow{2}{*}{ Districts } & \multicolumn{4}{|c|}{ All residents } & \multicolumn{4}{|c|}{ Males } & \multicolumn{4}{|c|}{ Females } \\
\hline & No. & $\operatorname{Mean} \pm \mathrm{SD}$ & Range & Median & No. & Mean \pm SD & Range & Median & No. & Mean \pm SD & Range & Median \\
\hline Heilongjiang & $30^{\ddagger}$ & $0.29 \pm 0.08^{\dagger}$ & $0.14-0.50$ & 0.29 & 15 & $0.33 \pm 0.08$ & $0.24-0.50$ & 0.33 & 15 & $0.28 \pm 0.08$ & $0.14-0.40$ & 0.27 \\
\hline Liaoning & 50 & $0.36 \pm 0.04$ & $0.25-0.44$ & 0.36 & 28 & $0.36 \pm 0.04$ & $0.25-0.44$ & 0.36 & 22 & $0.31 \pm 0.05$ & $0.27-0.34$ & 0.31 \\
\hline Hebei & 37 & $0.38 \pm 0.13$ & $0.11-0.68$ & 0.4 & 20 & $0.45 \pm 0.10$ & $0.24-0.68$ & 0.45 & 17 & $0.29 \pm 0.10$ & $0.11-0.47$ & 0.32 \\
\hline Henan & 45 & $0.38 \pm 0.16$ & $0.10-0.96$ & 0.37 & 20 & $0.44 \pm 0.16$ & $0.10-0.96$ & 0.41 & 25 & $0.33 \pm 0.15$ & $0.08-0.57$ & 0.32 \\
\hline Shaanxi & 48 & $0.29 \pm 0.12$ & $0.10-0.78$ & 0.28 & 31 & $0.30 \pm 0.06$ & $0.21-0.49$ & 0.29 & 17 & $0.27 \pm 0.16$ & $0.10-0.78$ & 0.26 \\
\hline Shanghai & 47 & $0.42 \pm 0.09$ & $0.17-0.65$ & 0.42 & 27 & $0.44 \pm 0.08$ & $0.24-0.55$ & 0.45 & 20 & $0.39 \pm 0.10$ & $0.17-0.65$ & 0.36 \\
\hline Hubei & 36 & $0.44 \pm 0.16$ & $0.06-0.79$ & 0.44 & 25 & $0.48 \pm 0.10$ & $0.29-0.72$ & 0.47 & 11 & $0.33 \pm 0.23$ & $0.06-0.79$ & 0.24 \\
\hline Sichuan & 34 & $0.43 \pm 0.24$ & $0.22-0.60$ & 0.4 & 15 & $0.52 \pm 0.33$ & $0.33-1.71$ & 0.43 & 19 & $0.35 \pm 0.09$ & $0.22-0.56$ & 0.32 \\
\hline Fujian & 42 & $0.40 \pm 0.37$ & $0.16-0.52$ & 0.37 & 28 & $0.58 \pm 0.59$ & $0.30-2.65$ & 0.42 & 14 & $0.32 \pm 0.11$ & $0.08-0.52$ & 0.31 \\
\hline Guangxi & 39 & $0.39 \pm 0.15$ & $0.11-0.68$ & 0.38 & 25 & $0.43 \pm 0.10$ & $0.18-0.54$ & 0.39 & 14 & $0.32 \pm 0.18$ & $0.11-0.68$ & 0.34 \\
\hline Total & 408 & $0.38 \pm 0.18$ & $0.06-2.65$ & 0.37 & 234 & $0.42 \pm 0.20$ & $0.10-2.65$ & 0.39 & 174 & $0.32 \pm 0.13$ & $0.06-0.79$ & 0.31 \\
\hline
\end{tabular}

${ }^{\ddagger}$ No. is number of samples; ${ }^{\dagger} \mathrm{SD}$ is standard deviation. 
Table 2. Human hair Se content from 1985 to 2011 (mg/kg) in residents from different Chinese districts.

\begin{tabular}{|c|c|c|c|c|c|}
\hline District & Province/City & Year & Sample Size & Average value & Range \\
\hline \multirow{13}{*}{ Northern } & Heilongjiang [17] & 1995 & 1232 & $0.47 \pm 0.20$ & \\
\hline & Heilongjiang [15] & 2011 & 27 & $0.26 \pm 0.08$ & $0.13-0.44$ \\
\hline & Heilongjiang $^{\dagger}$ & 2011 & 30 & $0.29 \pm 0.08$ & $0.14-0.50$ \\
\hline & Liaoning [18] & 1989 & 51 & $0.33 \pm 0.03$ & \\
\hline & Liaoning $^{\dagger}$ & 2011 & 50 & $0.36 \pm 0.04$ & $0.25-0.44$ \\
\hline & Jilin [19] & 1993 & 10 & 0.86 & $0.79-0.93$ \\
\hline & Beijing urban [20] & 1985 & 311 & $0.57 \pm 0.13$ & $0.33-0.82$ \\
\hline & Hebei $^{\dagger}$ & 2011 & 37 & $0.38 \pm 0.13$ & $0.11-0.68$ \\
\hline & Qinghai [21] & 2006 & 2272 & $0.28 \pm 0.15$ & $0.04-0.731$ \\
\hline & Inner Mongolia [22] & 1995 & 400 & 0.76 & $0.04-2.24$ \\
\hline & Shaanxi $^{\dagger}$ & 2011 & 48 & $0.29 \pm 0.12$ & $0.10-0.78$ \\
\hline & Henan [23] & 1997 & 53 & $0.68 \pm 0.20$ & \\
\hline & Henan $^{\dagger}$ & 2011 & 45 & $0.38 \pm 0$ & $0.08-0.96$ \\
\hline \multirow{16}{*}{ Southern } & Anhui [16] & 2003 & 266 & $0.39 \pm 0.10$ & \\
\hline & Jiangsu [24] & 1994 & 30 & $0.56 \pm 0.16$ & \\
\hline & Jiangsu [25] & 2006 & 53 & 0.34 & $0.10-0.62$ \\
\hline & Jiangsu [3] & 2011 & 285 & $0.32,0.39$ & \\
\hline & Shanghai urban[26] & 1986 & 200 & 0.72 & $0.29-1.8$ \\
\hline & Shanghai urban [27] & 1998 & 30 & 0.55 & \\
\hline & Shanghai urban ${ }^{\dagger}$ & 2011 & 24 & $0.38 \pm 0.09$ & $0.17-0.55$ \\
\hline & Shanghai suburb [26] & 1986 & 119 & 0.63 & $0.30-2.8$ \\
\hline & Shanghai suburb ${ }^{\dagger}$ & 2011 & 23 & $0.45 \pm 0.08$ & $0.31-0.65$ \\
\hline & Hubei [28] & 1988 & 20 & $0.62 \pm 0.08$ & \\
\hline & Hubei ${ }^{\dagger}$ & 2011 & 18 & $0.47 \pm 0.17$ & $0.06-0.72$ \\
\hline & Sichuan [29] & 1992 & 107 & $0.51 \pm 0.10$ & $0.26-0.71$ \\
\hline & Sichuan $^{\dagger}$ & 2011 & 34 & $0.43 \pm 0.24$ & $0.22-1.71$ \\
\hline & Guangdong [30] & 2000 & 72 & $0.50 \pm 0.12$ & \\
\hline & Guangxi $^{\dagger}$ & 2011 & 57 & $0.39 \pm 0.14$ & $0.11-0.79$ \\
\hline & Fujian $^{\dagger}$ & 2011 & 42 & $0.40 \pm 0.37$ & $0.08-2.65$ \\
\hline
\end{tabular}

\subsection{Hair Se Differences between Males and Females}

This survey encompassed 234 males and 174 females. The hair Se concentration of both males and females represented a normal statistical distribution (Figure 3). Generally, the hair Se content of males was higher than that of females (Table 1). There existed significant difference $(p<0.05)$ between hair Se concentration of males and females, except for Liaoning and Shaanxi in the northern areas. Moreover, the hair Se content of males exhibited a more dense statistical distribution than that of females. Among the 234 males, only one had hair Se content lower than $0.20 \mathrm{mg} / \mathrm{kg}$, and 14 (6\%) males had hair Se content lower than $0.25 \mathrm{mg} / \mathrm{kg}$. Among the 174 females, 34 (15\%) had hair Se content lower than $0.20 \mathrm{mg} / \mathrm{kg}$, while $17(7 \%)$ had Se content less than $0.25 \mathrm{mg} / \mathrm{kg}$. Thirty-eight males 
$(16 \%)$ and 15 females $(6 \%)$ had hair Se content greater than $0.50 \mathrm{mg} / \mathrm{kg}$. The tendency of females to be Se deficient may be related to Se intake because females generally eat less, especially staple food, than males.

Figure 3. The statistical distribution of hair Se content in males and females.
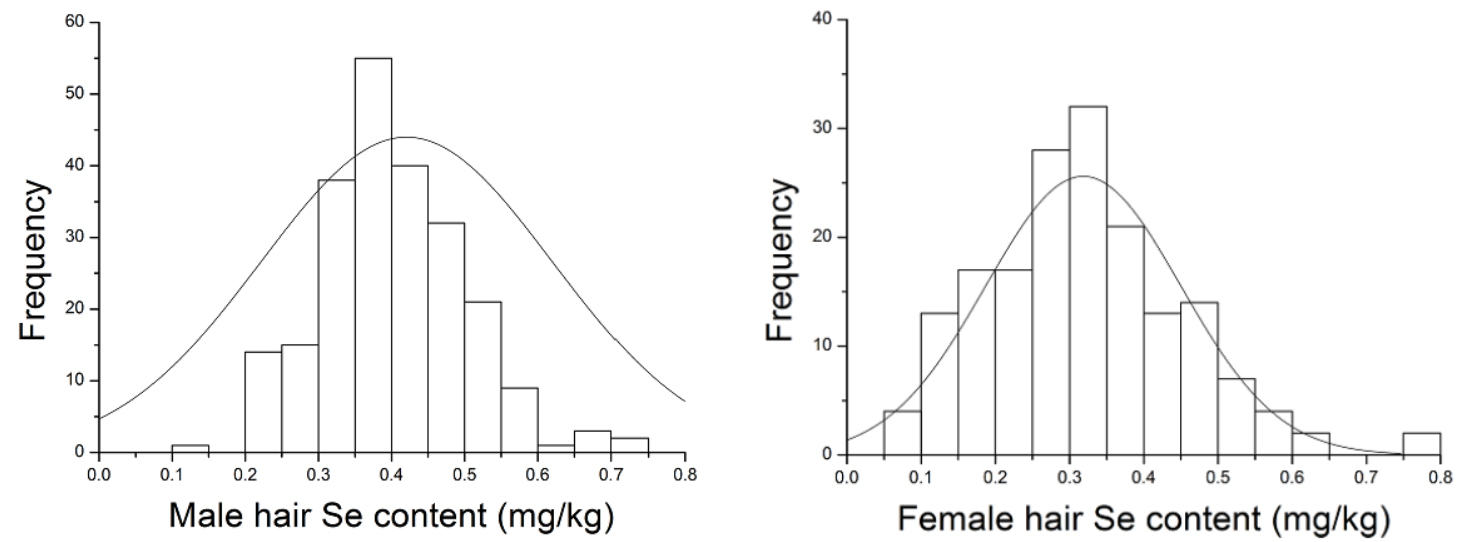

\subsection{Hair Se Differences in Chinese Residents between Current Data and Historical Data}

The hair Se content of residents in this survey was more similar to the results of studies conducted after 2000, but was significantly lower than that reported in the 1980s. In general, the hair Se content of residents reported before 2000 was greater than $0.50 \mathrm{mg} / \mathrm{kg}$, whereas that reported after 2000 was lower than $0.50 \mathrm{mg} / \mathrm{kg}$ (Table 2). When comparing current survey data with past reported data in the same province, there were significant decreases. The hair Se level of Heilongjiang residents $(0.29 \mathrm{mg} / \mathrm{kg}$ ) was reduced by $37 \%$ from $0.47 \mathrm{mg} / \mathrm{kg}$ reported in 1995 . The hair Se content of Henan residents $(0.38 \mathrm{mg} / \mathrm{kg})$ declined by $44 \%$ from $0.68 \mathrm{mg} / \mathrm{kg}$ reported in 1997 . The hair Se content of Hubei residents $(0.44 \mathrm{mg} / \mathrm{kg})$ decreased by $30 \%$ from $0.62 \mathrm{mg} / \mathrm{kg}$ reported in 1987 . The hair Se level of Sichuan residents $(0.43 \mathrm{mg} / \mathrm{kg})$ was $16 \%$ lower compared to $0.51 \mathrm{mg} / \mathrm{kg}$ reported in 1992 . In Shanghai, the survey showed that the Se concentration of $0.39 \mathrm{mg} / \mathrm{kg}$ was $46 \%$ lower compared to $0.72 \mathrm{mg} / \mathrm{kg}$ reported in 1986, and 34\% lower compared to $0.55 \mathrm{mg} / \mathrm{kg}$ reported in 1998 . The hair Se level in the suburban areas of Shanghai $(0.45 \mathrm{mg} / \mathrm{kg})$ decreased by $28 \%$ from $0.63 \mathrm{mg} / \mathrm{kg}$ reported in 1985, which represents a smaller degree of change compared with that in urban areas. In a similar long-term survey, Lyons also found a decline in human blood and plasma Se status in South Australia from the late 1970 s to 2003 [31].

\subsection{Factors that Influence Variations of Hair Se Content}

The concentrations of Se in rice, vegetables, meats, and fishes collected from the tested provinces above were determined as described in Table 3. According to the dietary structure and Se concentration of different foods of every province (reported from Chinese statistical yearbook 2011), the estimated daily Se intake per capita of every province varied from 11 to $31 \mu \mathrm{g} \mathrm{day}^{-1}$ (see Table 3 ). Moreover, there was significant linear correlation $(R=0.86, n=10)$ between daily Se intake of every province and corresponding hair Se content (Figure 4). The Se supplied by grains greatly influences the Se intake of residents. Assuming rice as the main source of grain, daily Se intake from rice was 
$34 \%-57 \%$ as the major food source, which significantly contributed to the daily human Se intake. In this survey, Se concentration of rice ranged from 19 to $31 \mu \mathrm{g} / \mathrm{kg}$, and the national average value of $24 \mu \mathrm{g} / \mathrm{kg}$ was less than the data reported in both of the other regions [3] and slightly less than the average Se concentration of $25 \mu \mathrm{g} / \mathrm{kg}$ in regular rice [32]. Furthermore, the Chinese residents dramatically reduced their rice consumption from 1985 to 2011 (Chinese statistical yearbook from 1985 to 2011). Using the rice average Se concentration to estimate the change of Se intake, the average Se intake from rice went from $9 \mu \mathrm{g}$ /day in 1985 to $6 \mu \mathrm{g}$ /day in 2011, indicating a decline of $40 \%$ (Table 4). According to the acceptable least daily intake of $50 \mu \mathrm{g}$ Se recommended by the Chinese Nutrition Society for adults, the Se intake supplied by rice accounted for $18 \%$ of the least daily intake in 1985 , and only $11 \%$ in 2011 . Calculations show that the daily Se intake of adults only ranges from 26 to $32 \mu \mathrm{g}$ in China [33], and the decrease of Se intake from grains constitutes a much larger proportion of the total dietary Se intake of adults. Similarly, the decrease of staple Se content contributed to a decrease of Se intake in the UK, where the Se intake fell from 60 to $63 \mathrm{ug} / \mathrm{day}$ to the current level of 34-39 ug/day [34]. This lower intake may be due to the reduced importation of North American (largely Canadian) wheat for bread-making, which was higher in Se content than the lower Se-containing EU wheat varieties.

Table 3. Selenium content in different foods and calculated daily Se intake for different Chinese districts.

\begin{tabular}{|c|c|c|c|c|c|c|c|c|c|}
\hline \multirow[b]{2}{*}{ Districts } & \multicolumn{4}{|c|}{ Se Concentration in Foods $(\mu \mathrm{g} / \mathrm{kg})$} & \multicolumn{4}{|c|}{ Food Consumption $(\mathrm{g}){ }^{\ddagger}$} & \multirow{2}{*}{$\begin{array}{c}\text { Se } \\
\text { Intake } \\
(\mu \mathrm{g} / \mathrm{day})\end{array}$} \\
\hline & Rice $^{\dagger}$ & Vegetable & Meat & Fish & Grain & Vegetable & Meat & Fish & \\
\hline Heilongjiang & 21 & 4.2 & 93 & 266 & 416 & 225 & 29 & 12 & 16 \\
\hline Niaoning & 20 & 4.5 & 86 & 249 & 472 & 306 & 41 & 14 & 18 \\
\hline Hebei & 23 & 7.7 & 91 & 263 & 456 & 216 & 26 & 9 & 17 \\
\hline Henan & 22 & 7.6 & 106 & 283 & 393 & 188 & 18 & 5 & 16 \\
\hline Shaanxi & 20 & 4.8 & 78 & 269 & 418 & 144 & 21 & 2 & 11 \\
\hline Shanghai & 19 & 5.5 & 111 & 234 & 396 & 190 & 59 & 51 & 27 \\
\hline Hubei & 30 & 6.1 & 152 & 348 & 445 & 361 & 49 & 23 & 31 \\
\hline Sichuan & 31 & 6.7 & 103 & 209 & 456 & 313 & 73 & 7 & 25 \\
\hline Fujian & 31 & 9.9 & 97 & 252 & 463 & 236 & 20 & 46 & 28 \\
\hline Guangxi & 25 & 9.8 & 109 & 276 & 490 & 240 & 46 & 11 & 23 \\
\hline
\end{tabular}

${ }^{\dagger}$ Se concentration expressed on a dry weight basis; ${ }^{\star}$ food consumption originated from Chinese statistical yearbook 2011.

Table 4. The Se concentration of rice and Se intake from grain.

\begin{tabular}{|c|c|c|c|c|c|c|c|}
\hline \multirow[b]{2}{*}{ Year } & \multicolumn{7}{|c|}{ The Se Intake from Grain of Urban Residents $(\mu \mathrm{g} / \mathrm{day})^{\dagger}$} \\
\hline & 1985 & 1990 & 1995 & 2000 & 2005 & 2010 & 2011 \\
\hline Grain consumption (g/person/day) & 369 & 358 & 266 & 226 & 211 & 223 & 221 \\
\hline $\begin{array}{c}\text { Se intake from grain } \\
(\mu \mathrm{g} / \mathrm{day}, \text { in the national average })\end{array}$ & 9 & 9 & 7 & 6 & 5 & 6 & 6 \\
\hline Percent of lowest daily intake for adult $(\%) *$ & 18 & 18 & 13 & 11 & 11 & 11 & 11 \\
\hline
\end{tabular}


Figure 4. The relationship between daily Se intake and hair Se content in different districts $(n=10)$.

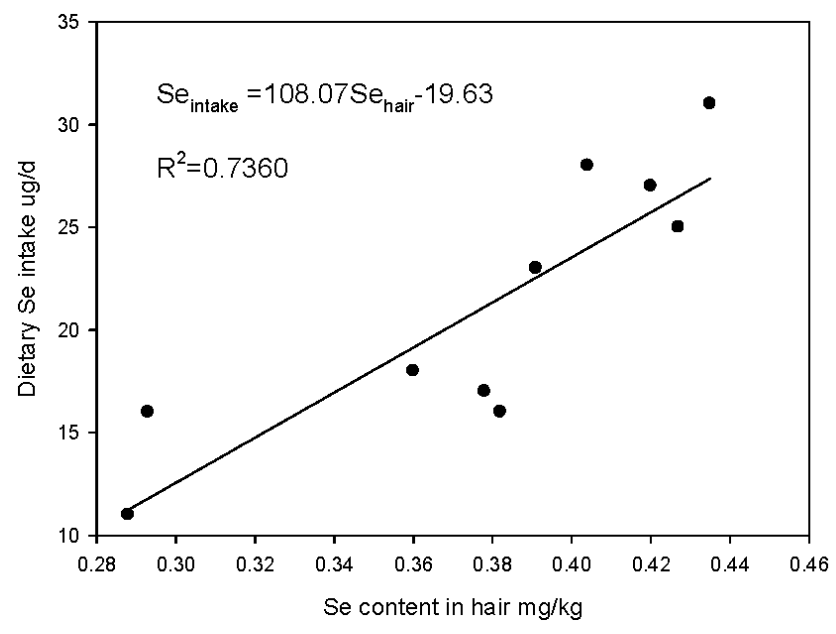

\section{Conclusions}

The survey results of the hair Se content presently show the variability among individuals, gender, and regional differences in residents from northeast to southeast China. The hair Se content of today's residents decreased by $24 \%-46 \%$ compared with past residents in the same geographic region. The decrease of hair Se content may be primarily related to the decrease of grain consumption and the lower Se content in the staple food rice.

\section{Acknowledgments}

We are grateful to the key projects in the National Science \& Technology Pillar Program in the Twelfth Five-year Plan (2012BAD15B03) for financial supports. We thank Xinhua Peng for the help collecting the human hair samples and Xihai Deng for analyzing the Se content of hair.

\section{Conflicts of Interest}

The authors declare no conflict of interest.

\section{References}

1. Rayman, M.P. The importance of selenium to human health. Lancet 2000, 356, 233-241.

2. Li, N.; Gao, Z.D.; Luo, D.G.; Tang, X.; Chen, D.F.; Hu, Y.H. Selenium level in the environment and the population of Zhoukoudian area, Beijing, China. Sci. Total Environ. 2007, 381, 105-111.

3. Gao, J.; Liu, Y.; Huang, Y.; Lin, Z.Q.; Bañuelos, G.S.; Lam, M.H.; Yin, X. Daily selenium intake in a moderate selenium deficiency area of Suzhou, China. Food Chem. 2011, 126, 1088-1093.

4. Tan, J.; Zhu, W.; Wang, W.; Li, R.; Hou, S.; Wang, D.; Yang, L. Selenium in soil and endemic diseases in China. Sci. Total Environ. 2002, 284, 227-235.

5. Rayman, M.P. Food-chain selenium and human health: Emphasis on intake. Br. J. Nutr. 2008, $100,254-268$. 
6. Clark, L.C.; Combs, G.F.; Turnbull, B.W.; Slate, E.H.; Chalker, D.K.; Chow, J.; Davis, L.S.; Glover, R.A.; Graham, G.F.; Gross, E.G.; et al. Effects of selenium supplementation for cancer prevention in patients with carcinoma of the skin A randomized controlled trial. JAMA 1996, 276, 1957-1963.

7. Choi, Y.; Kim, J.; Lee, H.; Kim, C.; Hwang, I.K.; Park, H.K. Selenium content in representative Korean foods. J. Food Comp. Anal. 2009, 22, 117-122.

8. Kazuko, H.; Katsuhiko, N.; Hiroshi, D. Selenium intake based on representative diets in Japan, 1957-1989. Nutr. Res. 1996, 16, 1471-1477.

9. Yang, G.Q.; Zhou, R.H.; Yin, S.A.; Pu, J.H.; Zhu, L.Z.; Liu, S.J. Study of selenium requirements for people. J. Hyg. Res. 1985, 14, 24-28.

10. Laker, M. On determining trace element levels in man: The uses of blood and hair. Lancet 1982, 2, 260-262.

11. Huang, Y.; Wang, Q.; Gao, J.; Lin, Z.; Bañuelos, G.S.; Yuan, L.; Yin, X. Daily dietary selenium intake in a high selenium area of Enshi, China. Nutrients 2013, 5, 700-701.

12. Research Group of Environment and Endemic Disease, Chinese Academy of Sciences. Geographical distribution of selenium content in human hair in Keshan disease and non-disease zones in China. Acta Geogr. Sin. 1982, 37, 136-143 (in Chinese).

13. Tan, J.A. The Atlas of Endemic Diseases and Their Environment; Science Press: Beijing, China, 1989.

14. Schroeder, H.A.; Frost, D.V.; Balassa, J.J. Essential trace metals in man: Selenium. J. Chronic Dis. 1970, 23, 227-243.

15. Chen, Y.Q.; Xu, X.Y.; Gao, Q. The selenium daily intake of the residents in the southern Songnen plain of Heilongjiang province. J. China West Norm. Univ. 2011, 32, 198-200.

16. He, J.H.; Zhang, Z. Investigation and evaluation of selenium nutrition in Huaibei inhabitants. J. Environ. Health 2008, 25, 426-428 (in Chinese).

17. Chen N.H. Determination of the hair selenium content of teenagers of Heihe suburb. Heihe Sci. Tech. 1995, 1, 18-19 (in Chinese).

18. Gao, S.X.; Liu, Y.Z. Determination of selenium content in the hair and urine of healthy individuals in Jinzhou. J. Jinzhou Med. Coll. 1989, 10, 158-161 (in Chinese).

19. Guo, D.; Li, S. Determination of selenium in human hair and urine of Changchun urban. J. Norman Bethune Univ. Med. Sci. 1993, 19, 512-513 (in Chinese).

20. Wei, H.C.; Chen, Q.; Huang, J.L. Background value of hair selenium content of healthy adults in Beijing. J. Beijing Med. Univ. 1985, 17, 288-291.

21. Yan, H.Z.; Shu, S.G.; Yuan, J.S.; Li, Y.; Liu, H.L.; Zhang, J.H. Study of selenium level distribution of people settled in Qinghai plateau regions. J. Qinghai Med. Coll. 2006, 27, 178-180 (in Chinese).

22. Li, Y.M.; Wang, L.Y.; Gao, H.P. Determination of hair selenium in healthy adults of Baotou city. J. Hyg. Res. 1995, 24, 152-153 (in Chinese). 
23. Bao, B.C.; Gou, G.X.; Bao, M.L.; Ding, B.R.; Xiao, R.G.; Zhang, L.Y.; Yang, M. Study on the content of hair Se and blood GSH-Px activity of people in endemic goiter, Keshan disease and Kaschin-Beck disease areas in Henan province. Guangdong Trace Elem. Sci. 1997, 4, 16-18 (in Chinese).

24. He, N.Z. Determination and analysis of the hair content of $\mathrm{Fe}, \mathrm{Zn}, \mathrm{Cu}, \mathrm{Mn}, \mathrm{Se}$ of undergraduate students. Chin. J. School Health 1994, 15, 219-220 (in Chinese).

25. Zhou, X.B.; Shi, W.M.; Wang, X.C.; Li, B.H.; Yang, L.Z. Evaluation of selenium nutrition of village/town inhabitants in south Jiangsu. Soils 2007, 39, 541-544 (in Chinese).

26. Zhang, F.Z.; Wu, T.G.; Tian, A.T.; Li, L.F.; Xiang, W.Z.; Jin, S.X. Hair selenium level of healthy individuals in Shanghai. Shanghai Environ. Sci. 1986, 8, 34-36 (in Chinese).

27. Qu, J.G.; Xu, B.X.; Gong, S.C. Investigation of selenium content in food and hair in Shanghai. J. Environ. Health 1998, 15, 185-186 (in Chinese).

28. Ni, X.; Chen, C.P. A survey of selenium nutritional status of Wuhan inhabitants. J. Wuhan Grain Ind. Coll. 1988, 2, 33-35 (in Chinese).

29. Li, F.Y.; Xiao, M.D.; Fan, R.H. Determination of selenium content of human hair in Luzhou. J. Luzhou Med. Coll. 1992, 15, 9-10 (in Chinese).

30. Li, X.L.; Li, X.J.; Li, Z.X. Investigation of hair Se level on healthy children and adults in Guangzhou region. Guangdong Trace Elem. Sci. 2000, 7, 27-28 (in Chinese).

31. Lyons, G.H.; Judson, G.J.; Stangoulis, J.C.R.; Palmer, L.T.; Jones, J.A.; Graham, R.D. Trends in selenium status of South Australians. Med. J. Aus. 2004, 180, 383-386.

32. Research Group of Environment and Endemic Disease, Chinese Academy of Sciences. Relationship between the distribution of Keshan disease and selenium concentration in food grain in China. Acta Geogr. Sin. 1981, 36, 369-376 (in Chinese).

33. Cheng, L.C.; Yang, F.M.; Xu, J.; Hu, H.; Hu, Q.H.; Zhang, Y.L.; Pan, G.X. Determination of selenium concentration of rice in China and effect of fertilization of selenite and selenate on selenium content of rice. J. Agric. Food Chem. 2002, 50, 5128-5130.

34. Rayman, M.P. The argument for increasing selenium intake. Proc. Nutr. Soc. 2002, 61, 203-215.

(C) 2014 by the authors; licensee MDPI, Basel, Switzerland. This article is an open access article distributed under the terms and conditions of the Creative Commons Attribution license (http://creativecommons.org/licenses/by/3.0/). 